Asian J. Med. Biol. Res. 2020, 6 (4), 623-627; doi: 10.3329/ajmbr.v6i4.51227

\author{
Asian Journal of \\ Medical and Biological Research \\ ISSN 2411-4472 (Print) 2412-5571 (Online) \\ www.ebupress.com/journal/ajmbr
}

\title{
Article \\ Determination of antibiotic residues in Black tiger shrimps (Penaeus monodon) and commercial shrimp feeds in Chattogram
}

Sharjil Mahmood, Nusrat sultana, Abdullah Al Mahmud, Sharmin Akter*, Md. Hossain Kabir and Suvanker Saha

Department of Medicine and Surgery, Chittagong Veterinary and Animal Sciences University, Khulshi, Chittagong, Bangladesh

${ }^{*}$ Corresponding author: Sharmin Akter, Department of Medicine and Surgery, Chittagong Veterinary and Animal Sciences University, Khulshi, Chittagong, Bangladesh. E-mail: sharmin_rhima@yahoo.com

Received: 12 October 2020/Accepted: 21 November 2020/ Published: 31 December 2020

\begin{abstract}
Shrimps are good source of protein and also good exportable item for its quality all over the world. Inappropriate use of antibiotics in the production of local and export quality shrimps can facilitate infiltration of antibiotic residues into human bodies which are toxic enough to cause serious health hazard. The present study was investigated to determine the antibiotic residues in some selected local market and export quality shrimps and also commercial shrimp feeds in chattogram. Local grade and export grade samples of Black tiger shrimps (Penaeus monodon) and feeds of four different companies were taken for the completion of this study. The permissible residual limit for the shrimp samples were- $0.3(\mu \mathrm{g} / \mathrm{kg})$ for Chloramphenicol and $1.0(\mu \mathrm{g} / \mathrm{kg})$ for AHD, AMOZ, SEM, AOZ. Black tiger shrimps from local market 1 had high concentration of Chloramphenicol $(0.35 \mu \mathrm{g} / \mathrm{kg})$ and SEM $(1.2 \mu \mathrm{g} / \mathrm{kg})$ residues whereas Market 2 showed maximum residues in AMOZ $(1.2 \mu \mathrm{g} / \mathrm{kg})$ and SEM $(1.1 \mu \mathrm{g} / \mathrm{kg})$. Whereas, Market 3 showed negative result. Local market 4 had high concentration of Chloramphenicol $(0.4 \mu \mathrm{g} / \mathrm{kg})$ and $\mathrm{AOZ}(1.2 \mu \mathrm{g} / \mathrm{kg})$ residues. However, in export grade shrimps antibiotic residues was found under the maximum residual limit in all samples. Also, among four feed tested, two of them were found positive for chlorampenicol and nitrofurans. The result was considered significant where P>0.05. So, legal actions should be taken against the farmers and the farms that overuse antibiotics in shrimps. Also, people should be made aware of the harmful effects of antibiotics so that the impact can be minimized.
\end{abstract}

Keywords: antibiotic residues; local and export quality shrimps; public health; Chattogram

\section{Introduction}

Marine shrimp (Penaeus monodon) represents the second largest exportable item which contributes to Gross Domestic Production (GDP) in Bangladesh (DoF, 2011). An antibiotic is drugs used to treat bacterial infections. Their main work is to kill or stop the growth of harmful bacteria. Antibiotics have been given to farm animals like cows, pigs and poultry and shrimps from the year 1940 in order to treat infections or prevent an illness from spreading. Low doses of antibiotics are also added to animal feed to promote their growth. This means a greater production of meat or milk or other productions in shorter periods of time. These low doses may also reduce animal death rates and improve reproduction (Boyd, 2001). Due to some beneficial effects, antibiotic has been used widely in agriculture. A report said that, $80 \%$ of all antibiotics sold in the United States were for use in food-producing animals in 2011. Antibiotics are mainly used for treating or preventing infections in animals or fishes. However, excessive or inappropriate use becoming less effective for both humans and animals and develop antibiotic resistancy. As a result, the antibiotics are no longer as effective at killing harmful bacteria, which is a great concern for public health (Landers et al., 2012). The US Food and Drug Administration (FDA, 2017) have recognized this concern, updating its regulations to reduce the unnecessary use of antibiotics in livestock. There are many debate remaining on antibiotic use in animals. According to the study of Van boeckel et al. (2014), antibiotic drugs consumption in worldwide increased by $36 \%$. Nitrofurans are synthetic broad- 
spectrum antibiotics, which are frequently used as growth promoters in animal production due to their excellent antibacterial and pharmacokinetic properties. Prohibition of nitrofurans for the treatment of animals used for food production was done because the parent compounds and their metabolites have carcinogenic and mutagenic characteristics. The European Union banned the nitrofurans furaltadone, nitrofurantoin and nitrofurazone for use in animals used as sources of food in 1993 and the use of furazolidone was also prohibited in 1995 (ECR, 1995). The analysis of nitrofurans is based on the detection of the tissue bound metabolites of nitrofurans which are present for a long time after administration. The parent compounds are difficult to detect accurately since they are metabolized very rapidly after treatment. There are different types of nitrofurans like Nitrofurantoin: 1 Aminohydantoin (AHD), Furaltadone: 3-Amino-5-morpholinomethyl-2-oxazolidinone (AMOZ), Furazolidone: 3-Amino-2oxazolidinone (AOZ), Nitrofurazone: Semicarbazide (SEM).

Due to the carcinogenic and toxic properties of antibiotic residues and their allergic potential, the consumption of contaminated food promotes great risk to public health as well as inappropriate use causes multi-drug resistance of pathogen bacteria for antibiotics used in human medicine.

The purpose of this study is to find a better understanding of the current situation of the shrimps which are overdosed with the antibiotics in Chattogram. The antibiotics remain as residues which when get inside the human bodies through the consumption of shrimps can cause serious damage to human health.

\section{Materials and Methods}

\subsection{Sample collection and transportation}

For the analysis of antibiotic residues in the shrimp, samples of Black tiger shrimps (Penaeus monodon) from the four local market $(n=20)$, six export oriented shops $(n=30)$ and four kinds of feeds $(F 1-F 4)$ were taken. The samples were transported to the laboratory in the day one to perform the test. From the local grade shrimp and export grade shrimp, residues of Chloramphenicol, AOZ, AMOZ, AHD, and SEM were measured and from feeds, chlorampenicol and nitrofurans were detected though it is concerened by Fish Inspection and Quality Control (FIQC), Bangladesh.

\subsection{Sample preparation}

The samples were prepared according to protocol described (Sarwer et al., 2017).

\subsection{Standard solutions preparation for ELISA}

Standard solutions of Chloramphenicol, AOZ, AMOZ, AHD, and SEM were prepared from the stock solutions according to protocol provided (Sarwer et al., 2017). ELISA (Enzyme Linked Immunosorbent Assay) was applied to determine the level of antibiotic residues in the collected samples (Sarwer et al., 2017). AOZ (type R3703) and AMOZ (R3711), AHD (NF3463), SEM (NF3461) and ELISA kit with chloramphenicol were purchased. The resulting color intensity was measured at the spectrophotometer at $450 \mathrm{~nm}$ using an ELISA reader/micro plate reader (ELx 800, BioTek, USA).

\subsection{Statistical analysis}

All the results expressed are the mean of these measurements. Data were presented as mean \pm standard deviation. To test the differences between groups, one way ANOVA was performed. To find out significance between local and export grade t-test was performed and considered significant when $\mathrm{P}<0.05$. Statistical analyses were performed using SPSS 20.0 for windows (SPSS, Chicago, IL, USA) and Microsoft Excel 2007.

\section{Results}

The results of antibiotic residues conducted on shrimp samples collected from local market, export oriented shops and feed manufacturing companies were presented in Table 1.

From the Table 1, it was clearly evident that, after the ELISA test on the four market samples of the local grade shrimp Penaeus monodon contained the residues of some of the antibiotics. Chloramphenicol was present in the sample collected from Market 1 and 4. AOZ (Furazolidone or 3-Amino-2oxazolidinone) was present in the sample collected from Market 4. AMOZ (3-amino-5-morpholino-methyl-1, 3-oxa- zolidinone) was present in the sample of Market 2. SEM (semicarbazide) was present in both sample of Market 1 and 2.

The bar diagram (Figure 1) shows that, Chloramphenicol and SEM were found in two local market shrimp samples that is $50 \%$. On the other hand, $\mathrm{AOZ}$ and $\mathrm{AMOZ}$ were evident in the single market sample represents $25 \%$ and AHD was under the maximum residue limit in all shrimp sample.

From the Table 2, it can be clearly noted that export quality shrimps are not entirely free of residues of the antibiotics. But the residues are present in the samples in the permissible limits. 
From the Tables 1 and 2, the average concentration of CAP, AOZ, AMOZ, AHD and SEM was 0.3 \pm .09 , $0.73 \pm .32,0.7 \pm .35,0.53 \pm .11$ and $0.97 \pm .22 \mu \mathrm{g} / \mathrm{kg}(\mathrm{P}<0.05)$ respectively in the shrimp sample of local market

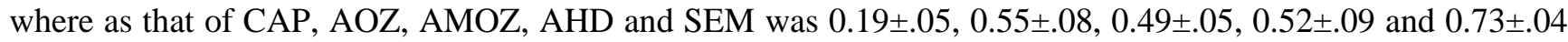
$\mu \mathrm{g} / \mathrm{kg}$ respectively in the Export grade shrimp sample.

From the Table 4 it is clear that, the Chloramphenicol and Nitrofurans was detected in 2 different feed samples out of 4 samples that were collected from four feed factories.

Table 1. Selected antibiotic residues in local grade shrimps.

\begin{tabular}{llllll}
\hline Parameters & Chloramphenicol & AOZ & AMOZ & AHD & SEM \\
Reference Value $(\mu \mathrm{g} / \mathrm{kg})$ & 0.3 & 1.0 & 1.0 & 1.0 & 1.0 \\
Market 1 & $\mathbf{0 . 3 5}$ & 0.5 & 0.7 & 0.5 & $\mathbf{1 . 2}$ \\
Market 2 & 0.25 & 0.7 & $\mathbf{1 . 2}$ & 0.45 & $\mathbf{1 . 1}$ \\
Market 3 & 0.2 & 0.55 & 0.5 & 0.7 & 0.9 \\
Market 4 & $\mathbf{0 . 4}$ & $\mathbf{1 . 2}$ & 0.4 & 0.5 & 0.7 \\
Mean \pm SD & $0.3 \pm .09$ & $0.73 \pm .32$ & $0.7 \pm .35$ & $0.53 \pm .11$ & $0.97 \pm .22$ \\
Level of significance & $\mathrm{S}$ & $\mathrm{S}$ & $\mathrm{S}$ & $\mathrm{S}$ & $\mathrm{S}$ \\
\hline
\end{tabular}

* $\mathrm{SD}=$ Standard Deviation, $* \mathrm{~S}=$ significant

Table 2. Selected antibiotic residues in export grade shrimp.

\begin{tabular}{llllll}
\hline Parameters & Chloramphenicol & AOZ & AMOZ & AHD & SEM \\
Reference value $(\mu \mathrm{g} / \mathrm{kg})$ & 0.3 & 1.0 & 1.0 & 1.0 & 1.0 \\
Shop 1 & 0.15 & 0.6 & 0.5 & 0.5 & 0.25 \\
Shop 2 & 0.15 & 0.5 & 0.5 & 0.7 & 0.7 \\
Shop 3 & 0.2 & 0.55 & 0.5 & 0.5 & 0.5 \\
Shop 4 & 0.25 & 0.5 & 0.4 & 0.55 & 0.5 \\
Shop 5 & 0.15 & 0.5 & 0.55 & 0.4 & 0.5 \\
Shop 6 & 0.7 & 0.8 & 0.5 & 0.7 \\
Mean \pm SD & 0.25 & $0.55 \pm .08$ & $0.49 \pm .05$ & $0.52 \pm .09$ & $0.73 \pm .04$ \\
Level of Significance & $0.19 \pm .05$ & $\mathrm{~S}$ & $\mathrm{~S}$ & $\mathrm{~S}$ & $\mathrm{~S}$ \\
\hline
\end{tabular}

$*$ S= Significant

Table 3. T-test for comparison of both local grade and export grade shrimps.

\begin{tabular}{lll}
\hline Antibiotic residues & Local grade & Export grade \\
Chloramphenicol & 2.465036 & $\mathbf{0 . 0 3 9 0 1 1}$ \\
AOZ & 1.348 & 0.214 \\
AMOZ & 1.458 & 0.183 \\
AHD & 0.187 & 0.856 \\
SEM & 2.682484 & $\mathbf{0 . 0 2 7 8 1 9}$ \\
\hline
\end{tabular}

In Student's independent t-test (Table 3), in export grade shrimp chloramphenicol and nitrofuran $(\mathrm{p}<0.05)$ were found significant.

Table 4. Feed analysis result.

\begin{tabular}{lll}
\hline Sample & Chloramphenicol & Nitrofurans \\
Feed 1 & - & - \\
Feed 2 & - & + \\
Feed 3 & + & - \\
Feed 4 & - & - \\
\hline
\end{tabular}

$(+)=$ Detected,$(-)=$ Not detected 


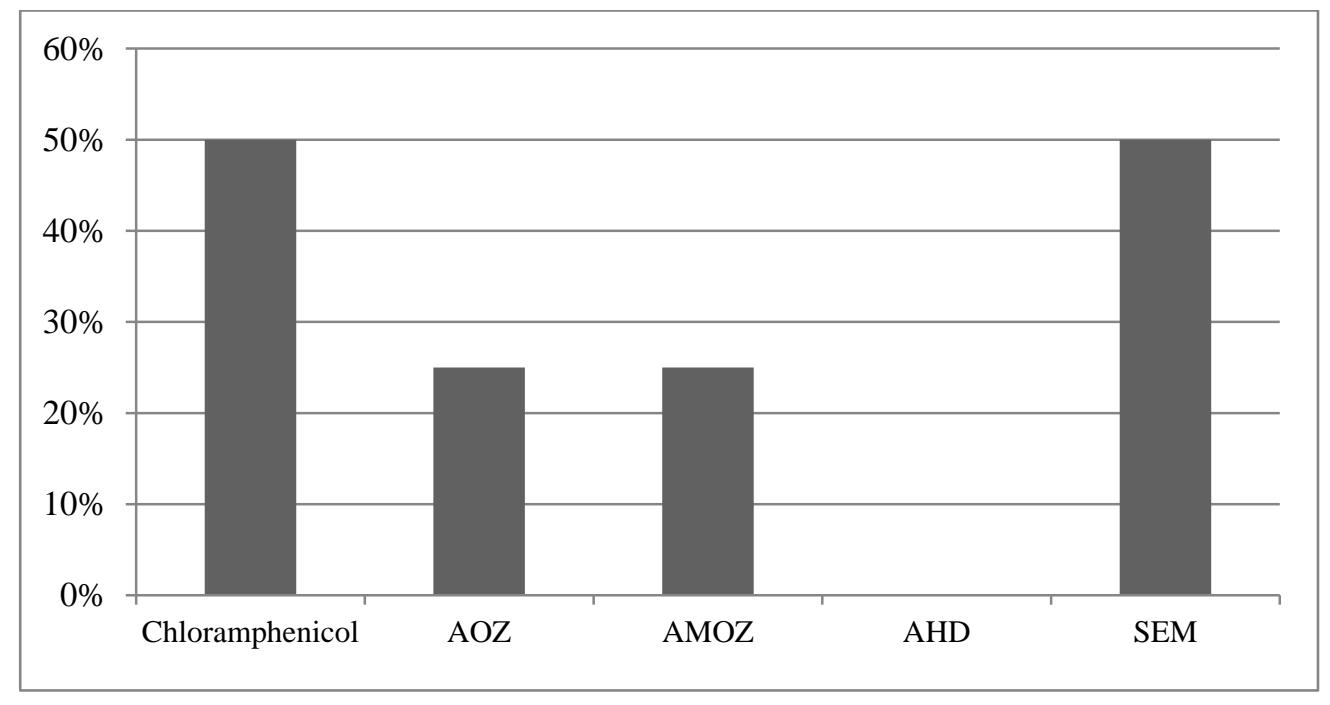

Figure 1. Distribution of antibiotic residues in local grade shrimps.

\section{Discussion}

Shrimp aquaculture has become most popular worldwide for its export quality value (Swapna et al., 2012). Shrimps are known as good source of protein (Dayal et al., 2013). But in order to increase the growth rate of shrimp and enhance immunity, a high amount of antibiotics are given to the shrimps along with its feed (Swapna et al., 2012). Before the washing or withdrawal period of these antibiotics, shrimps are being sold to the markets and customers. So, the antibiotics remain in the shrimps as residues. A massive effort is required to reduce the use of antibiotics in animals is one of main issues listed by the WHO (WHO, 1999).

The present study was planned to detect the antibiotic residues in some selected local market shrimp and export quality shrimp and also commercial shrimp feeds in Chattogram. From this study, local grade shrimp Penaeus monodon contained the residues of some of the selected antibiotics like Chloramphenicol, AOZ (Furazolidone or 3-Amino-2oxazolidinone), AMOZ (3-amino-5-morpholino-methyl-1, 3-oxa-zolidinone) and SEM (semicarbazide) respectively.

Another study shows that, Nitrofuran metabolites, furazolidone (AOZ), nitrofurazone (SEM) were the major causes of notifications by RASFF (RASFF, 2014), followed by Chloramphenicol and Oxytetracycline. Among the total notifications, 39\% were from black tiger shrimps in which mostly antibiotic residues was found from AOZ (Rao et al., 2015). In our study, mostly antibiotic residues found from chlorampenicol in local grade shrimp which is different from this study.

Another researcher showed that, in three years 2008-10, AMOZ, AOZ, AHD, SEM and CAP were found significantly above maximum residual limit in shrimp muscles (Hassan et al., 2013) which is coordinate with our study.

However, in this study, in export grade shrimps antibiotic residues was found under the maximum residual limit in six export oriented shops. Another study revealed that, these banned antibiotics were detected in many $M$. rosenbergii and P. monodon samples in 2008, 2009 and 2010, in both fresh muscles, pre-export and post-export consignments (Hassan et al., 2013).

In this study, among four feed samples, CAP and nitrofuran metabolites were found positive in two samples. Another study claimed that, among the 160 feed samples, 38 were found contaminated with CAP and/or nitrofuran metabolites (AMOZ, AOZ, AHD and SEM) (Islam et al., 2014).

A large proportion of shrimp farmers in the Thai coast used antibiotics in their farms in shrimp pond management, some used them prophylactically, some on a daily basis, and at least thirteen antibiotics were used (Holmstrom et al., 2003).

In our study, Chloramphenicol and SEM were found in two local market shrimp samples (50\%) out of four local market samples. On the other hand, AOZ and AMOZ were evident in the single sample of two different market represents $25 \%$ and AHD was under the maximum residual limit in all shrimp samples. In case of the export grade samples, it was found that all the shrimp samples had no antibiotic residues left in them. In case of the feed testing, chloramphenicol and nitrofurans were detected in two different feed samples out of 4 samples that were collected from different feed factories. According to FDA, chloramphenicol, and nitrofurans are prohibited to be used in the aquaculture farming (FDA, 2017). So, there is an alarming concern regarding the use of antibiotics in the aquaculture farming. 
The result indicates a concern for the common people in Bangladesh who consume shrimps from local market on a daily basis. These antibiotic residues that were found in the Black tiger shrimp can seriously pose risk to these people.

\section{Conclusions}

The residual antibiotics can deteriorate human health when consumed. So, strict policies should be made and laws and regulations should be applied to those who are behind this heinous act. Also it is mandatory to let people know about the antibiotic residues in shrimp and their harmful health effect so that they can minimize the consumption of these shrimps.

\section{Acknowledgements}

The author would like to acknowledge the stuffs of the Department of Applied Chemistry and Chemical Technology and Research supervisor, Chattogram veterinary and animal sciences university, Bangladesh for their cordial supports during the work.

\section{Conflict of interest}

None to declare.

\section{References}

Boyd W, 2001. Making meat: Science, technology, and American poultry production. Technol. Cult., 42: 631664.

Dayal JS, AG Ponniah, HI Khan, EM Babu, K Ambasankar and KK Vasagam, 2013. Shrimps-a nutritional perspective. Current Science, 1487-1491.

DoF, 2011. National Fisheries Week. Department of Fisheries, Bangladesh, Souvenir, 20-26 July.

European Commission Regulation, 1995. 1442/95/EC of the Comission of 26 June on amending Annexes I, II, III and IV of Council Regulation (EEC) No. 2377/90 laying down a Community procedure for the establishment of maximum residue limits of veterinary medicinal products in foodstuffs of animal origin. Official J. L., 143: 26-30.

Hassan MN, M Rahman, MB Hossain, MM Hossain, R Mendes and AAKM Nowsad, 2013. Monitoring the presence of chloramphenicol and nitrofuran metabolites in cultured prawn, shrimp and feed in the Southwest coastal region of Bangladesh. Egypt. J. Aquat. Res., 39: 51-58.

Holmström K, S Gräslund, A Wahlström, S Poungshompoo, BE Bengtsson and N Kautsky, 2003. Antibiotic use in shrimp farming and implications for environmental impacts and human health. Int. J. Food Sci. Technol., 38: 255-266.

Islam MJ, AA Liza, AM Reza, MS Reza, MNA Khan and M Kamal, 2014. Source identification and entry pathways of banned antibiotics nitrofuran and chloramphenicol in shrimp value chain of Bangladesh. EurAsian J. Biosci., 8: 71-83.

Landers TF, B Cohen, TE Wittum and EL Larson, 2012. A review of antibiotic use in food animals: perspective, policy, and potential. Public Health Rep., 127: 4-22.

Rao BM and MM Prasad, 2015. Residues of Veterinary Medicinal Products (antibiotics) in shrimp exported from India to the European Union (EU) trends in the last decade.

RASFF, 2014. The Rapid Alert System for Food and Feed 2013 Annual Report, European Commission, European Union.

Sarwer MG, MMH Rony, MS Sharmin, AJ Chowdhury and S Bhowmik, 2017. ELISA validation and determination of cut-off level for chloramphenicol (CAP) residues in shrimp and fish. Our Nature, 15: 13-18.

Swapna KM, R Rajesh and PT Lakshmanan, 2012. Incidence of antibiotic residues in farmed shrimps from the southern states of India. Indian Journal of Geo Marine Sciences, 41: 344-347.

U.S. Food and Drug administration (FDA), 2017.

Van Boeckel TP, S Gandra, A Ashok, Q Caudron, BT Grenfell, SA Levin and R Laxminarayan, 2014. Global antibiotic consumption 2000 to 2010: an analysis of national pharmaceutical sales data. Lancet Infect. Dis., 14: 742-750.

World Health Organization and Joint FAO/NACA/WHO Study Group on Food Safety Issues Associated with Products from Aquaculture, 1999. Food safety issues associated with products from aquaculture: report of a joint FAO/NACA/WHO study group (Vol. 883) 